\title{
Teoria e ideologia do desenvolvimento à luz das contribuições de Celso Furtado
}

\author{
Theory and ideology of development in the light of Celso Furtado's contributions
}

Michelle Paranhos

\begin{abstract}
Doutoranda do Programa de Pós-Graduação em Políticas Públicas e Formação Humana da Universidade do Estado do Rio de Janeiro (PPFH-UERJ) michelle.paranhos@gmail.com
\end{abstract}

\begin{abstract}
Resumo: Este artigo pretende abordar, a título introdutório, a temática do desenvolvimento econômico e da interpretação teórica do subdesenvolvimento, tendo em vista a contribuição intelectual de Celso Furtado. O primeiro momento apresenta as linhas gerais da ideologia e da teoria do desenvolvimento, tendo em vista sua origem e seus conteúdos. Em seguida, busca-se apontar os principais aspectos da base material capitalista que proporcionou a formulação e a difusão dessa ideologia após a Segunda Guerra Mundial, no contexto da concepção estadunidense de guerra fria. Por último, procura-se delinear o enraizamento da ideologia do desenvolvimento na América Latina, levando em consideração a concepção da Comissão Econômica para América Latina (CEPAL), que inaugura uma nova perspectiva teórica do desenvolvimento latino-americano, que Celso Furtado leva à forma mais radical, no sentido de explicá-la e aprofundá-la.
\end{abstract}

Palavras Chaves: Celso Furtado; Subdesenvolvimento; Ideologia do desenvolvimento.

\begin{abstract}
This article intends to address, as an introductory title, the theme of economic development and the theoretical interpretation of underdevelopment, in view of Celso Furtado's intellectual contribution. The first moment presents the general lines of ideology and development theory, considering its origin and its contents. Then, we seek to point out the main aspects of the capitalist material base that provided the formulation and diffusion of this ideology after the Second World War, in the context of the American cold war conception. Finally, it seeks to delineate the rooting of development ideology in Latin America, taking into account the conception of the Economic Commission for Latin America (ECLAC), that inaugurates a new theoretical perspective about the Latin American development that Celso Furtado takes to the most radical form, in the sense of explaining and deepening it.
\end{abstract}

Keywords: $\quad$ Celso $\quad$ Furtado; Underdevelopment; Ideology of development. 
Este artigo $^{1}$ aborda, a título introdutório, a temática do desenvolvimento econômico e da interpretação teórica do subdesenvolvimento, a partir da contribuição intelectual de Celso Furtado. Busca-se reunir elementos da obra do autor que possam levar à compreensão da formação social brasileira e do processo histórico e ideológico do desenvolvimento do capitalismo no Brasil e na América Latina, a fim de subsidiar análises posteriores da política educacional brasileira ${ }^{2}$.

Furtado emergiu nos anos 1950, consolidando-se como pensador econômico e como cientista social, durante esta década, quando trabalhou como pesquisador e analista da Comissão Econômica para América Latina (CEPAL). Destacando-se no panorama desenvolvimentista brasileiro, a teorização de Furtado e da CEPAL se converteu na mais importante ideologia industrialista da época, influenciando e determinando políticas concretas e a ação de vários governos latino-americanos. Sua contribuição, neste sentido, não pode ser compreendida se deslocada do debate mais amplo sobre o desenvolvimento e subdesenvolvimento, já que Furtado foi uns dos intelectuais que mais se dedicou ao tema.

O termo desenvolvimento, que desde o final da Segunda Guerra Mundial, marcou e ainda marca, a narrativa da história mundial e o pensamento políticointelectual, enraizou-se fortemente no Brasil, organizando o pensamento e o debate das ciências sociais no país, principalmente no campo econômico. Abarcando distintos projetos de variadas origens e filiações políticas - caracterizados ou não como desenvolvimentistas -, a ideologia do desenvolvimento foi e permanece sendo hegemônica no cenário político-intelectual do Brasil contemporâneo, o que sublinha a atualidade das teorizações de Celso Furtado.

Embora a contribuição do autor tenha sido tomada como superada pelos ideólogos do neoliberalismo, deixando a sua bibliografia preterida nos cursos de economia e no debate público a partir da década de 1990, as questões propostas por

\footnotetext{
${ }^{1}$ Este artigo integra o estudo apresentado como trabalho de conclusão para a Disciplina "Tópicos Especiais: História como Método e Processo e a Produção de Conhecimento Científico", ministrada no segundo semestre de 2019, pelo Professor Gaudêncio Frigotto, no Programa de Pós-Graduação em Políticas Públicas e Formação Humana da Universidade do Estado do Rio de Janeiro (PPFH-UERJ).

${ }^{2}$ É importante destacar que não será abordada no presente texto a relação entre desenvolvimento e políticas públicas de educação, que constitui o tema da dissertação de mestrado - "Teoria e ideologia do desenvolvimento capitalista: na abordagem das concepções educacionais e das políticas públicas de formação dos trabalhadores no Brasil" - e que será aprofundado durante o doutorado. Nesses estudos, partimos da ideologia do desenvolvimento como chave de análise do fenômeno educacional, tendo em vista a relação entre projetos societários e concepções educacionais. A ideologia do desenvolvimento ganha especificidade na educação através da noção de capital humano (FRIGOTTO, 2006), que se redefine a partir dos anos 1990, nas concepções de competências para a empregabilidade e capital social (PARANHOS, 2010).
} 
Furtado voltam à cena diante da evidente insuficiência da estratégia neoliberal de desenvolvimento em retomar o ritmo de acumulação dos "anos gloriosos" do capitalismo. A retomada da temática se dá por um motivo aparentemente simples: como o desenvolvimento permanece inalcançável, a cada marco histórico, o problema do "subdesenvolvimento" se reapresenta com força redobrada.

Nessa direção, busca-se apreender o contexto histórico a partir do qual se constitui a obra de Celso Furtado. Para isso, o texto estrutura-se em três tópicos: num primeiro momento, são apresentadas as linhas gerais da ideologia e da teoria do desenvolvimento, tendo em vista seus conteúdos e sua origem; em seguida, busca-se apontar os principais aspectos da base material capitalista que proporcionou a formulação e a difusão dessa ideologia após a Segunda Guerra Mundial, no contexto da concepção estadunidense de guerra fria. Por último, procura-se delinear o enraizamento da ideologia do desenvolvimento na América Latina, levando em consideração as contribuições do pensamento da CEPAL e nova perspectiva teórica que a agência inaugura acerca do desenvolvimento latino-americano, dentro da qual Celso Furtado se destaca como um de seus intelectuais mais radicais.

Tendo como ponto de partida de sua investigação a economia brasileira em seu processo de industrialização, Celso Furtado destacou-se por reconhecer que os problemas específicos do subdesenvolvimento mereciam uma interpretação teórica própria. $\mathrm{O}$ autor buscou demonstrar através de sua obra e de sua atuação política, a insuficiência e a inadequação das teorias europeias e estadunidenses sobre o desenvolvimento econômico para abordagem do problema no Brasil e nos demais países da América Latina. Nos marcos da teoria do desenvolvimento, a teorização cepalinofurtadiana recoloca a discussão sob novos termos, constituindo as economias e sociedades subdesenvolvidas como objeto específico de estudo, sob o método históricoestrutural.

\section{Teoria e ideologia do desenvolvimento}

[...] os mitos operam como faróis que iluminam o campo de percepção do cientista social, permitindo-lhe ter urna visão clara de certos problemas $e$ nada ver de outros, ao mesmo tempo que lhe proporcionam conforto intelectual, pois as discriminações valorativas que realiza surgem ao seu espírito como um reflexo da realidade objetiva. Celso Furtado, O mito do desenvolvimento econômico, 1974 
O desenvolvimento é uma ideologia ${ }^{3}$. No entanto, precisamos considerar que sua eficácia e aceitação apoiam-se, em grande medida, na pretensa cientificidade e rigor da teoria da qual ela é portadora. Enquanto teoria e ideologia, o desenvolvimento redefine e renova as orientações políticas e ideológicas das velhas questões do progresso e da evolução. E, embora pareça sempre fora de alcance, nos últimos 70 anos e atualmente, o desenvolvimento vem sendo compreendido como um objetivo a ser perseguido, e desde o seu enraizamento, a temática nunca deixou de estar presente no debate políticointelectual latino-americano.

Segundo Celso Furtado (1974: 14), no terceiro quartel do século XX, noventa por cento da literatura encontrada nas ciências sociais fundava-se na ideia, que se dava como evidente, a partir da qual "o desenvolvimento econômico, tal qual vem sendo praticado pelos países que lideraram a revolução industrial”, poderia ser universalizado. Como nos mostra a epígrafe, o autor destaca o papel diretor do mito do desenvolvimento econômico nas ciências sociais, como uma "prolongação do mito do progresso, elemento essencial na ideologia diretora da revolução burguesa e na criação da sociedade industrial".

A origem da ideologia do desenvolvimento situa-se no contexto que se formou após Segunda Guerra Mundial, no interior da concepção de guerra fria (que a própria teoria do desenvolvimento ajudou a materializar), como parte da consolidação da hegemonia estadunidense e da construção da hegemonia do próprio capitalismo. A teoria do desenvolvimento foi produzida, em órgãos governamentais e foi ganhando como espaço de difusão os centros de pesquisa, universidades e as agências internacionais do capital. Economistas, sociólogos, antropólogos, cientistas políticos, psicólogos, entre outros, voltaram suas pesquisas para o atendimento das novas demandas de expansão do capitalismo, dando origem à construção social de ideias e valores que apresentavam o desenvolvimento econômico como "fim político incontestável" (PRADO, 2015).

\footnotetext{
${ }^{3}$ Por se tratar de um conceito polissêmico, o termo ideologia, mesmo dentro do campo marxista, apresenta diferentes entendimentos. Não se tem a intenção de estabelecer aqui uma definição para o termo, no entanto, é importante destacar que se parte da compreensão de que o desenvolvimento engendra uma estratégia ideologizante, pois esvazia os elementos históricos e particulares das sociedades de capitalismo dependente. Aqui, tomaremos a categoria ideologia como um sistema de crenças, valores e representações que se autoproduzem nas sociedades de classes com o objetivo de explicar, justificar e legitimar o sistema de dominação e estrutura material de exploração. Nesse sentido, a possibilidade de depurar e desvelar a ideologia é perpassada pela luta de classes e se dá através do discurso crítico vinculado à consciência da classe dominada.
} 
O ponto é que os aparelhos privados e estatais de hegemonia existentes nos países capitalistas ditos centrais, sob a égide dos Estados Unidos, estimularam e orientaram a produção de teorias sobre o 'desenvolvimento', tendo como foco a superação do 'subdesenvolvimento' de outros países. Nas potências dominantes capitalistas, sobretudo no mundo anglo-saxão, formouse naquele então a já mencionada "economia do desenvolvimento" (PRADO, 2015: 52, grifo do autor).

Surgiu assim uma profusão bibliográfica de tradição neoclássica que se inscreve no campo que recebeu a denominação de "economia do desenvolvimento", objetivo fundamental foi pautado pela questão de como desenvolver as regiões que, a partir daquele momento, passariam a ser classificadas como "subdesenvolvidas". Essas análises tinham como propósito definido explicar e justificar as desigualdades que caracterizam as relações econômicas sob o modo de produção capitalista e responder à inconformidade das ex-colônias latino-americanas - que desde os anos 1910 já se orientavam na direção da industrialização e que buscavam se integrar à expansão do capitalismo internacional - e do conjunto de novas nações que emergiam dos processos de independência das colônias asiáticas e africanas no final dos anos 1940 e no decorrer da década de 1950.

Sob aparente rigor científico, a "teoria do desenvolvimento econômico" buscava "explicar, numa perspectiva macroeconômica, as causas e o mecanismo do aumento persistente da produtividade do fator trabalho e suas repercussões na organização da produção e na forma como se distribui e se utiliza o produto social" (FURTADO, 2009: 25). Tais teorias apresentavam-se não apenas como suporte teórico para o subdesenvolvimento, mas também como eixo para a proposição de metas gerais elaboradas com base nas economias "desenvolvidas" - que os países deveriam seguir para superá-lo. As análises fundamentavam-se na construção de modelos ou esquemas teóricos dos sistemas econômicos existentes, que buscavam explicar o "problema do

\footnotetext{
4 Moraes (2006, 2005) examina a reflexão ocidental sobre o desenvolvimento, focalizando alguns cientistas sociais que participam da fundação do pensamento modernizador no período entre 1940 e 1960 , situando suas obras emblemáticas em dois grupos: o primeiro seria constituído pelos teóricos da economia do desenvolvimento de formação neoclássica e keynesiano-neoclássica - entre os intelectuais que se destacaram nesse campo estavam Willian Arthur Lewis, Paul Rosentein, Ragnar Nurske, Walt Whitman Rostow, Hans Singer, Norman Buchanan, Howard Ellis, Gerald M. Méier, Robert Baldwin, Charles Kindleberger, Irma Adelman, entre outros - e o segundo grupo seria constituído pelos cientistas sociais de outras áreas formados na tradição funcionalista - tendo entre seus representantes Talcott Parsons, Daniel Lerner, Edward Shils, Marion Levy, Jr., Gabriel Almond, LucianPye, David Riesman, David M. Potter, Bert Hoselitz, David McClelland, Alex Inkeles.
} 
subdesenvolvimento" igualando o "desenvolvimento" a determinados processos históricos de países industrializados.

Embora destaque a importância da compreensão dos modelos baseados na observação do comportamento histórico e na estrutura social das economias industrializadas, Furtado pressupõe que a tarefa explicativa da teoria do desenvolvimento projeta-se não apenas no plano abstrato, mas fundamentalmente, no plano histórico, destacando a necessidade do confronto do modelo explicativo com a realidade dada e a singularidade de cada fenômeno de desenvolvimento. Empreende nessa direção a crítica ao método neoclássico e a sua elevação à categoria de abstração universal e a-histórica, buscando construir um modelo teórico que aproximava a análise econômica e o método histórico, tomando empréstimos de vários campos teóricos redefinidos em uma nova teorização inteiramente original. Segundo Furtado:

As características da realidade social e política latino-americana são ignoradas na maioria desses estudos, que se limitam a uma análise dos fatores econômicos pertinentes, sobretudo, aqueles relacionados com o comércio exterior e com as finanças públicas. Ocorre, entretanto, que, embora as variáveis econômicas possam ser definidas a partir de princípios gerais de economia, o comportamento dessas variáveis está condicionado por parâmetros institucionais, cujo conhecimento exige um estudo específico da realidade social (FURTADO, 2011: 119).

$\mathrm{Na}$ concepção dos economistas do desenvolvimento, o processo histórico em questão passa a ser compreendido de forma idealizada, o que se desdobra no entendimento de que as observações feitas em um modelo possuem validez e alcance universal para explicação do processo de desenvolvimento em geral. Esse mecanismo engendra uma estratégia ideológica que cumpre papel desistoricizante, ao esvaziar os elementos particulares dos processos históricos e naturalizar o desenvolvimento capitalista.

Como se todas as sociedades estivessem dispostas ao longo de uma mesma escala, o desenvolvimento se define, no interior dessa ideologia, como a passagem de um padrão de sociedade "arcaico", "atrasado", "semicolonial" a um padrão "moderno", supondo a consolidação do capitalismo como uma mudança natural intrínseca a toda sociedade, um processo contínuo necessário e que seria alcançável por todos os países. No interior dessa escala, o subdesenvolvimento representaria uma etapa prévia do 
desenvolvimento.

Sendo assim, as obras vinculadas ao campo da economia do desenvolvimento dispensavam a necessidade de tratar historicamente as mudanças sociais, tomando como referência um modelo constituído a partir de um tipo de sociedade ideal e abstrata para analisar toda e qualquer sociedade, em qualquer tempo e lugar. Dentro dessa concepção, desenvolvimento e subdesenvolvimento eram explicados a partir do mesmo modelo ou esquema teórico.

\section{As bases materiais da ideologia do desenvolvimento}

Embora os processos históricos determinantes ${ }^{5}$ da ideologia do desenvolvimento antecedam 1945, foi somente a partir desse período, que a base material capitalista que possibilitaria a universalização desse constructo ideológico se estabeleceu. As transformações do padrão de reprodução do capital que se processaram em escala mundial, sob a hegemonia dos EUA (para o qual as duas últimas guerras haviam sido economicamente benéficas), permitiram que diferentes projetos de desenvolvimento se tornassem hegemônicos. A ideologia do desenvolvimento surgiu, então, como um desdobramento conveniente, no momento histórico em que uma nova hegemonia estava se constituindo nos processos mais dinâmicos do novo curso da expansão do capitalismo, no qual se colocavam como pauta a reconstrução das economias devastadas pela guerra e a preocupação com as necessidades de expandir os mercados na Ásia, América Latina e África, fortalecendo o capitalismo.

As potências imperialistas europeias entraram em declínio, apresentando dificuldades para manterem suas antigas conquistas territoriais, permitindo que um conjunto de novos Estados juridicamente soberanos emergissem dos processos de independências das colônias asiáticas e africanas, no final dos anos 1940 e no decorrer da década de 1950. A aliança provisória entre capitalismo e comunismo que havia se formado contra o nazismo e o fascismo, deu lugar à Guerra Fria. Nos centros

\footnotetext{
5 São determinantes para a formação da ideologia do desenvolvimento processos históricos que antecedem 1945 - tais como a Primeira Guerra Mundial, a Revolução Russa de 1917, a Crise de 1929, o Keynesianismo, os processos de descolonização da Ásia e África, a Segunda Guerra Mundial - no entanto, é somente a partir do fim da Segunda Guerra que a própria base material capitalista possibilitará a universalização desse constructo ideológico, permitindo que diferentes projetos de desenvolvimento se tornem hegemônicos.
} 
hegemônicos do capitalismo, consolidavam-se as técnicas de produção tayloristasfordistas $^{6}$ aliadas aos mecanismos de estabilização construídos a partir da reconfiguração do Estado que, sob os pressupostos keynesianos, teve que assumir novos papéis, na medida em que a produção de massa requeria demandas efetivamente estáveis para dar lucros, demarcando o período de crescimento econômico que ficou conhecido como "anos de ouro" do capitalismo.

Na América Latina, o período que se seguiu à Segunda Guerra foi marcado por novas contradições entre classes e segmentos de classe. O setor industrial que se desenvolvia modestamente em países da região, já no final do século XIX, ganhou novos contornos a partir da crise do capitalismo que se estabeleceu entre os dois conflitos mundiais. A crise de 1929 e suas repercussões sobre a economia contribuíram para acelerar o processo de industrialização através da substituição das importações, consolidando a formação de uma camada de trabalhadores assalariados e de frações da classe dominante ligadas à indústria que vinham formulando e disputando a orientação da política econômica com o setor agrário-exportador no sentido do avanço da industrialização. Esse cenário favorecia a difusão das teorias que buscavam formular uma orientação para o desenvolvimento econômico capitalista.

Em "O mito do desenvolvimento econômico", Furtado (1974) analisa as consequências do segundo conflito mundial, sob a tendência de uma crescente unificação do sistema capitalista, que se manifestam no plano econômico mediante à afirmação das grandes empresas no quadro de oligopólios internacionais, ao crescimento explosivo do mercado financeiro, ao processo de integração das economias nacionais que formam o centro do sistema e à rápida industrialização da periferia do sistema capitalista no quadro de uma nova configuração da divisão internacional do trabalho, sob a tutela dos Estados Unidos. Segundo o autor, esse período corresponde à terceira fase $^{7}$ da evolução capitalista, cujo traço mais característico está na transformação das funções dos Estados e na emergência de uma nova forma de

\footnotetext{
6 Não sem motivos, a consolidação das técnicas de produção tayloristas-fordistas foi um processo histórico prolongado e se deu sob fortes resistências das classes trabalhadoras. Foi preciso o quasecolapso do capitalismo na década de 1930, para que se desencadeassem as intensas transformações que possibilitariam a sua acomodação após 1945. Da mobilização dos trabalhadores, decorreu o aumento das tensões sociais que levou a novos arranjos de poder e à adequação dos modos e mecanismos de intervenção estatal. Em casos como o da Alemanha e Japão forças políticas do militarismo e da extrema direita ascenderam ao poder.

7 A primeira fase da evolução do capitalismo industrial corresponde, para Furtado, ao período iniciado na segunda metade do século XIX, enquanto a segunda fase, situa-se entre 1870 e a primeira guerra mundial, corresponde à reação ao projeto inglês de economia mundial.
} 
organização política, na qual "as grandes empresas" assumem o papel de centro de decisão da economia mundial. Observa-se assim uma mudança qualitativa do investimento externo nos países periféricos.

Em primeiro lugar, as grandes empresas controlam a inovação - dentro das economias nacionais, certamente o principal instrumento de expansão internacional. Em segundo lugar, elas são responsáveis por grande parte das transações internacionais e detêm praticamente a iniciativa nesse terreno; em terceiro lugar, operam internacionalmente sob orientação que escapa em grande parte à ação isolada de qualquer governo, e, em quarto, mantêm uma grande liquidez fora do controle dos bancos centrais e têm fácil acesso ao mercado financeiro internacional (FURTADO, 1974: 33).

Após a Segunda Guerra, os Estados Unidos orientaram-se no sentido da organização de uma "sociedade internacional 'aberta", reiterando o processo de integração das economias que formam o centro do sistema. Para ter êxito, essa "sociedade de nações requeria a implantação de uma disciplina internacional" (FURTADO, 2011: 17), voltada para instituir a liberdade do movimento de capital, liberando a ação das empresas das limitações criadas pelos sistemas monetários e financeiros dos Estados nacionais. "Criou-se assim uma superestrutura política a nível muito alto, com a missão de desobstruir o terreno ali onde os resíduos dos antigos Estados Nacionais persistiam em criar barreiras entre os países" (FURTADO, 1974: $35)$.

Iniciou-se, deste modo, a construção de diversas instituições que formalmente buscavam estabelecer "um método de ação diplomática", com o objetivo de estruturar um espaço econômico unificado no centro do sistema capitalista, operando através de um sistema unificado de segurança comandado pelos Estados Unidos (FURTADO, 1974, 2011).

As negociações que vinham acontecendo no decorrer da Segunda Guerra Mundial e que se consolidaram, em 1944, nos acordos de Bretton Woods já sinalizavam os novos contornos que a dinâmica internacional do capitalismo assumiria. Com a criação do Banco Internacional para Reconstrução e Desenvolvimento (BIRD), do Acordo Geral para Tarifas e Comércio (sigla em inglês GATT) e do Fundo Monetário Internacional (FMI) pretendia-se instituir a hegemonia dos Estados Unidos no âmbito monetário. Entre as principais disposições do sistema estava a consolidação do padrão 
dólar-ouro, através do qual o preço oficial do ouro em dólar era mantido fixo e o dólar substituía de vez a libra como moeda-chave nas transações internacionais.

As circunstâncias particulares do pós-guerra - que fizeram dos Estados Unidos por um decênio, único país com oferta elástica no plano internacional, única fonte de bens de capital e único centro capaz de fornecer financiamento de médio e longo prazos - permitiram que as instituições de Bretton Woods se consolidassem e transformassem o dólar no instrumento de acumulação de uma liquidez que tendia a crescer com o volume das transações internacionais. Dessa forma, os Estados Unidos adquiriram o privilégio de emitir moeda de curso internacional, isto é, de imprimir papelmoeda que, por ter garantia do governo norte-americano, possuía poder libertatório em todos os países do mundo (FURTADO, 2011: 55-56).

Esses acordos proporcionavam a projeção, no plano internacional, das grandes empresas estadunidenses estruturadas em oligopólios, configurando a nova forma de organização monetária e financeira que elas demandavam para penetrar nos países que buscavam a industrialização. Nesse sentido, tal como afirma Baer et al. (1995), a ordem monetária que se instaurou a partir dos anos 1940 se afastou bastante das convenções estabelecidas em Bretton Woods e a função efetiva do acordo, mais do que definir as regras, foi importante na legitimação da absoluta soberania estadunidense no campo monetário internacional.

Dentro desse "sistema unificado de segurança", também foi instituída a Organização Mundial das Nações Unidas (ONU). Com o objetivo de "manter a paz e a segurança internacionais", em sua carta fundacional, a ONU apontava para o desenvolvimento econômico e social como resultado da cooperação internacional. Com a rápida reconstrução das econômicas da Europa Ocidental e do Japão, os organismos internacionais que, inicialmente, voltavam-se para as economias industrializadas, foram tomando como tarefa promover o desenvolvimento nos países ainda não industrializados.

Foi nesse contexto, que o debate sobre desenvolvimento ganhou evidência, e os países que antes eram classificadas como bárbaros, atrasados, agrários, semicoloniais e semifeudais, entre outros termos passaram a ser denominados subdesenvolvidos. Prado (2015) destaca que a dualidade entre desenvolvimento e subdesenvolvimento representa um processo de redefinição da hegemonia dos Estados Unidos, que começa a se 
generalizar com a intensificação das tensões políticas a partir de 1947, quando se inicia a Guerra Fria, nos termos da Doutrina Truman. Pela primeira vez na história moderna, houve uma bipolarização das forças, que tornou obsoletos os métodos de se fazer política internacional.

Não surpreende que estudiosos vejam na guerra fria uma engenhosa técnica de convivência entre nações utilizada nessa época que repentinamente se tornaram ultrapassados os métodos tradicionais da diplomacia e da guerra, sem que antes tivesse sido criado um novo sistema de relações internacionais viável. Com efeito, a doutrina da guerra fria surgiu nos Estados Unidos como uma hábil alternativa ao uso da força militar na política de “contenção" da União Soviética (FURTADO, 2011: 18-19).

Em “Raízes do Subdesenvolvimento", livro publicado originalmente em 2003, Celso Furtado faz uma nova leitura de ensaios escritos entre os anos de 1964 e 1968, no intuito de superar insuficiências decorrentes da percepção da guerra fria apresentada por ele anteriormente como fruto da realidade histórica daquela época. O autor destaca que a guerra fria é uma construção dos ideólogos de Washington "hoje percebida como um simples mito, que se dissolveu no ar no decênio de 1980, com a queda do Muro de Berlim” (FURTADO, 2011: 8). Combinando métodos diplomáticos e ação militar indireta, a doutrina da guerra fria $^{8}$ baseava-se na ideia de que a União Soviética precisava ser "contida".

O fantasma de uma nova guerra foi engendrado como arma de difusão da ideologia capitalista. Hoje todos admitimos que em nenhum momento houve risco efetivo de guerra total [...]. Os riscos assumidos pelos atores de maior relevo suscitaram em todos eles tamanho pavor que já ninguém pensou em repetir esse tipo de experiência (FURTADO, 2011: 27).

Para os Estados Unidos, o problema fundamental era o da sua própria "segurança", dessa forma, a doutrina da guerra fria buscava assegurar, num primeiro plano, que as formas de organização mundial fossem compatíveis com o american way of life dentro do seu próprio território e, num segundo plano, assegurar a preeminência

\footnotetext{
${ }^{8}$ A doutrina da guerra fria foi apresentada pelo historiador diplomático George F. Kennan, membro do Departamento de Estado estadunidense, como um conjunto consistente de ideias baseadas na possibilidade de um conflito armado entre EUA e URSS, na necessidade de "contenção" da URSS e do comunismo.
} 
de seus interesses econômicos pra além de suas fronteiras, garantindo objetivos de expansão e fortalecimento do capitalismo, bem como a reafirmação da hegemonia dos Estados Unidos frente à União Soviética e às demais nações.

Não obstante, para os Estados nacionais capitalistas, a tutela política estadunidense foi apresentada como "um sistema de segurança abrangente do conjunto do mundo capitalista", como um "instrumento de defesa da civilização ocidental”, como se não estivesse ligada aos interesses econômicos diretos dos Estados Unidos (FURTADO, 1974: 35). Em meio ao clima psicológico criado pela guerra fria, a opinião pública tinha como evidente a possibilidade de um novo conflito armado, o que fazia com que a liderança dos EUA fosse aceita não apenas pelos países industrializados da Europa Ocidental e pelo Japão, mas também pelos países da Ásia, África e América Latina que buscavam a industrialização.

A estratégia de segurança estadunidense engendrada pela guerra fria constituiuse como um dos principais alicerces da ideologia do desenvolvimento. Do ponto de vista da segurança territorial, qualquer interferência militar exterior em suas áreas de influência seria impedida pelo poder estratégico dos Estados Unidos. A questão que se evidenciava era, no entanto, se a tutela estadunidense poderia garantir a estabilidade social interna dos países, sem a qual necessariamente a segurança seria precária. Para além dos aspectos puramente militares, a segurança nacional era concebida como a segurança do modo de viver ocidental, fundado na defesa da democracia, da propriedade privada e do livre mercado. E foi justamente quando as populações pobres adquiriram consciência da situação de exploração e das diferenças nos níveis de vida de uma classe para outra ou de um país para o outro que tais "liberdades" passaram a ser vistas como ameaçadas.

Regiões nas quais as condições de vida se mostravam precárias representavam, a partir desta visão, terrenos férteis para a penetração de "ideologias antidemocráticas". Dessa forma, os teóricos do desenvolvimento, tal como Rostow, passaram a difundir a tese de que a "ajuda externa" aos países subdesenvolvidos, seria necessária para que os Estados Unidos alcançassem mais rápido seus objetivos políticos e econômicos. A partir dessas teses:

Admite-se que o processo de desenvolvimento pode ser orientado de fora para dentro, devendo ser o objetivo dos Estados Unidos "criar Estados, independentes, modernos e em desenvolvimento". Todo problema estaria em 
ajudar os países subdesenvolvidos a vencer as dificuldades iniciais e a alcançar o ponto de "desenvolvimento autossustentado". Está implícito nessa tese que superada as dores anteriores do take-off, já não haveria nenhum risco de instabilidade social (FURTADO, 2011: 34).

Já em escritos publicados nas décadas de 1960 e 1970, Furtado delineava os traços essenciais de um novo sistema que iriam prevalecer em um futuro não muito distante, buscando orientar suas análises a partir de hipóteses explicativas do comportamento que se mostrava atual e das tendências de longo prazo da economia mundial.

Como país líder, os Estados Unidos empenharam-se na criação de estruturas supranacionais que pudessem viabilizar esse sistema, assegurando a estabilidade social interna dos países sob a sua tutela por meio de "ajuda militar" aliada à "ajuda econômica". No interior desse "sistema unificado de segurança" instituído, a penetração estadunidense na chamada periferia do sistema capitalista, assumiu a forma, praticamente exclusiva de inserção dos grandes conglomerados. Ou seja, a "ajuda econômica", que já era escassa e que deveria ser proporcionada por programas de financiamento público estadunidenses para industrialização desses países, foi interrompida ou nunca se concretizou, forçando a América Latina e as demais regiões a aceitarem a participação direta das empresas privadas como intermediárias da política de "ajuda" dos Estados Unidos para o desenvolvimento das regiões "subdesenvolvidas" (FURTADO, 1974, 2011).

Como ideologia dominante, portanto, o desenvolvimento não poderia ficar restrito à sua própria classe, aos Estados Unidos e à Europa, nem somente aos meios científicos e políticos. Na perspectiva de seus ideólogos, para que uma autêntica política de desenvolvimento tivesse força, era necessário que um conjunto de valores se amalgamasse aos ideais de uma coletividade. Reconhecia-se que os processos de industrialização e modernização capitalista não poderiam se dar apenas no plano material, era necessária a formação de uma nova mentalidade, novos comportamentos e motivações para a classe trabalhadora e para as classes médias em consonância com as burguesias. Foi através da construção social do crescimento econômico como fonte de melhoria e elevação do padrão de vida das populações que o desenvolvimento se transformou em aspiração coletiva. O poder e peso simbólico e cultural do desenvolvimento como fim político incontestável materializavam-se ao mesmo tempo 
em que se alimentavam das práticas políticas e sociais: todos deveriam fazer sacrifícios em nome do desenvolvimento.

\section{O enraizamento da ideologia do desenvolvimento na América Latina e as contribuições da CEPAL}

Embora a ideologia do desenvolvimento tenha surgido a partir do projeto geopolítico de consolidação da hegemonia estadunidense no mundo capitalista e de fortalecimento do próprio capitalismo durante a guerra fria, conforme foi apresentado, ela se enraíza na América Latina, não apenas pela vinculação direta à esfera de influência dos Estados Unidos, mas fundamentalmente devido às contradições sociais internas da região.

Diferentemente dos novos países que emergiam dos processos de descolonização, os países da América Latina já haviam engendrado estruturas capitalistas e Estados nacionais e desde o final do século XIX, já haviam iniciado seus processos de industrialização, a partir do compromisso entre as burguesias industriais nascentes e as antigas oligarquias primário-exportadoras. A América Latina era, portanto, um cenário profícuo para uma ideologia que apontava a industrialização como o caminho para o desenvolvimento.

Segundo Furtado (2011) o processo de industrialização na América Latina compreende duas fases bem definidas. A primeira fase, que se estende do fim do século XIX até 1929, tem como fator dinâmico a elevação da renda nacional e a expansão do mercado interno, apoiada na exportação de produtos primários. A segunda fase, que se estende pelos três decênios seguintes, tem uma complexidade bem maior, caracteriza-se pelas tensões estruturais motivadas pelo declínio da capacidade para importar.

A crise de 1929 representa, assim, um ponto de inflexão (ou de ruptura) no padrão de divisão internacional do trabalho fundado na existência de países produtores de manufaturas versus países produtores de matérias-primas, dando ao setor industrial latino-americano que, até aquele momento, havia apresentado crescimento modesto, um novo estímulo externo. Furtado (2011: 137) analisa que a crise mundial de 1929 e a depressão prolongada que a ela se segue, para grande parte dos países da América Latina, teriam iniciado um processo de reversão da inserção no sistema de divisão internacional do trabalho que assumiu duas formas: a primeira consistiu em um 
processo de "reversão dos fatores antes utilizados em atividades dependentes do setor externo ao âmbito da economia pré-capitalista, na agricultura ou no artesanato"; a segunda forma consistiu na industrialização, que nas economias latino-americanas assume a forma de um processo de substituição das importações.

As transformações estruturais que se operaram nesse período, guardadas as devidas especificidades das economias latino-americanas, de um modo geral, se expressam socialmente no surgimento das burguesias industriais e de um novo contingente de trabalhadores assalariados, evidenciando novas contradições nas relações de força entre os grupos políticos. O que se pretende enfatizar aqui é que as transformações que ocorreram na periferia do sistema capitalista não foram mero reflexo da economia internacional, mas decorreram, fundamentalmente, das condições estruturais internas que permitiram a acumulação e o crescimento do mercado interno. É através das ações concebidas internamente pelas classes dirigentes que se criam as condições institucionais para a expansão das atividades ligadas ao mercado interno, marcando o início de uma nova fase da economia latino-americana, de desenvolvimento da estrutura produtiva de base urbano-industrial.

A interrupção quase total da oferta externa em decorrência da guerra, durante os anos 1940, permitem que os processos de industrialização tenham continuidade e se intensifiquem, firmando o espaço para a difusão da ideologia do desenvolvimento e para a mentalidade "desenvolvimentista".

Nos anos que se seguiram à Segunda Guerra Mundial, as econômicas latinoamericanas estavam em pleno processo de industrialização e urbanização, potencializado pelo rápido crescimento de 5,8\% ao ano entre 1945 e 1954, e por uma folga na restrição externa que permitiu uma expansão das importações em 7,5\% ao ano nesse mesmo período. Isso abria espaço ao fortalecimento da ideologia industrializante, que apenas vinha dando os primeiros passos na região. Ao mesmo tempo, disseminava-se a ideia de que as exportações tradicionais tendiam a recuperar o terreno com a volta à normalidade no pós-guerra, potencializando a restauração da ideologia liberal dominante até os anos 1930, fundamentada do ponto de vista acadêmico, na teoria da divisão internacional do trabalho baseada nas vantagens comparativas ricardianas (BIELSCHOWSKY, 2000: 24). 
Nesse sentido, "a volta da normalidade no pós-guerra" introduziu o processo de reconstrução das economias devastadas pela guerra que se instaurava na direção da restauração da divisão internacional do trabalho existente antes da guerra, mantendo a indústria como estratégia central dos países “desenvolvidos”, enquanto aos países não industriais do sistema relegava o papel de produzir matérias-primas e produtos agrícolas.

As novas formas que está assumindo o capitalismo nos países periféricos não são independentes da evolução global do sistema. Contudo parece inegável que a periferia terá crescente importância nessa evolução, não só porque os países cêntricos serão cada vez mais dependentes de recursos naturais nãoprodutíveis por ela fornecidos, mas também porque as grandes empresas encontrarão na sua mão-de obra barata um dos principais pontos de apoio para firmar-se no conjunto do sistema (FURTADO, 1974: 59).

Como parte do esforço de guerra, as tecnologias e técnicas compatíveis com o padrão de acumulação fordista foram implantadas na Europa e no Japão, através de políticas como o Plano Marshall ou da participação direta de capitais privados subsequente. Em contrapartida, na América Latina, as condições eram bem menos favoráveis, a ajuda externa só começa com a Aliança para o Progresso, mesmo assim em quantidades insuficientes. Já que para competir com esses países, que tiveram uma rápida recuperação, as economias latino-americanas precisavam elevar a produtividade do trabalho, lançando mão da "ajuda externa" sob a forma de equipamentos e técnicas, o financiamento externo da região tornou-se dependente da expansão do investimento direto das grandes empresas estadunidenses. Frente à ampliação da penetração dos capitais privados, as burguesias industriais latino-americanas optaram por associar-se a esses capitais, beneficiando-se das linhas de crédito e da transferência de tecnologias, que embora fossem obsoletas para os países industrializados, eram avançadas para a América Latina.

Para Furtado, o que caracteriza uma economia dependente é o papel subalterno que nela desempenha o progresso tecnológico. Ao contrário da ordenação dos fatores primários de impulsão que caracterizam o desenvolvimento autônomo, em que o progresso tecnológico precede a acumulação e as mudanças estruturais decorrentes da alteração no perfil da demanda, no processo de desenvolvimento dependente, essa sequência seria inversa: as modificações na composição da demanda seria o primeiro 
fator, seguido da acumulação e, por último, o progresso técnico.

A afirmação da mentalidade desenvolvimentista só foi possível a partir das determinações sociais constituídas pelos interesses econômicos concretos que estavam sendo postos no interior das economias latino-americanas. As classes dominantes voltavam-se para a industrialização e para não voltar ou não permanecer subordinada aos esquemas da velha divisão internacional do trabalho dos anos anteriores a 1930, governada pelas vantagens comparativas. Frente à possibilidade de retomada do liberalismo econômico após o fim da Segunda Guerra Mundial, o enraizamento da ideologia do desenvolvimento na América Latina, se fez a partir de determinações sociais próprias, que resultaram na emergência do pensamento da CEPAL, consolidado na teoria do subdesenvolvimento, que refletia os interesses econômicos concretos e o conflito das frações burguesas nacionais com o capital estrangeiro.

Com o objetivo de difundir a ideologia do desenvolvimento nos países da América Latina, as teorizações cepalinas fundavam-se na ideia de que o processo de industrialização e/ou a plena consolidação do capitalismo nos países latino-americanos seria a resposta para os problemas causados pelo subdesenvolvimento.

Durante a primeira década de funcionamento da CEPAL (1949-1959), Celso Furtado foi um de seus principais expoentes e contribuiu para instituir um programa de pesquisa específico, no qual as economias e sociedades subdesenvolvidas forma definidas como objeto de estudo, empreendendo a crítica aos postulados da economia clássica e apontando a emergência de fenômenos que não eram analisados pelos teóricos do desenvolvimento estadunidenses e europeus até então.

Ainda que nos marcos da ideologia do desenvolvimento, já que mantêm o desenvolvimento como "horizonte utópico" e a "questão motora" de como se desenvolver como pauta principal (PRADO, 2015), a teorização cepalino-furtadiana instituiu uma transformação crucial da discussão sobre desenvolvimento e subdesenvolvimento, recolocando-a sobre novos termos. Surgem, assim, uma profusão de noções e conceitos, como "deterioração dos termos de troca", "industrialização via substituição das importações", "divisão centro-preferia”, entre outros que vigoram até hoje na análise econômica.

O ponto de partida para a compreensão das contribuições cepalinas para a história das ideias econômicas deve ser, portanto, a especificidade do corpo analítico desenvolvido pela CEPAL, cuja força explicativa deriva da interação entre enfoque metodológico (histórico) e uma referência abstrato-teórica, a teoria do 
subdesenvolvimento periférico da América Latina (BIELSCHOWSKY, 2000).

Para os autores cepalinos, o desenvolvimento nas condições da periferia latinoamericana não se tratava de uma fase necessária ao processo universal de desenvolvimento a lá Rostow, mas dizia respeito a um processo cujos desdobramentos históricos seriam singulares, podendo dar origem a sequências e resultado distintos daqueles ocorridos nas economias ditas centrais.

A oposição entre "centro" e "periferia" exerce uma dupla-função analítica que ilustra a interação entre método e abstração teórica do subdesenvolvimento. Num primeiro plano, as estruturas subdesenvolvidas seriam determinadas como "periferia" do sistema capitalista pelo seu tipo específico de inserção na divisão internacional do trabalho, cujo papel na economia mundial é o de produtora de bens primários e importadora de produtos manufaturados, que absorve dos centros do sistema padrões de consumo e tecnologias. Ao mesmo tempo, a inserção "periférica" determina um modo específico de industrialização, crescimento econômico, introdução do progresso técnico e tecnológico, distribuição de renda e absorção da força de trabalho.

Um dos conceitos centrais das análises cepalino-furtadianas é o de desenvolvimento desigual, que deriva das desigualdades nas relações econômicas internacionais entre o "centro" e a "periferia". Nessas relações, comandadas por uma suposta "vantagem comparativa" do centro do sistema, a periferia leva uma desvantagem que se deve à deterioração dos termos de troca de seus produtos, que possuem menor valor agregado. A “deterioração dos termos de troca”, consistia assim, num elemento central das desigualdades entre centro e periferia, culminando no desenvolvimento desigual e periférico das economias da América Latina, marcado pela subordinação e pelo atraso. O subdesenvolvimento é tomado como resultado desse processo. A solução para o problema seria a "industrialização via substituição das importações", permitindo o desenvolvimento de outros setores produtivos no interior das economias periféricas. Para sair do círculo vicioso do subdesenvolvimento, seria necessária às regiões periféricas, a superação do "profundo dualismo nas estruturas produtivas" criado pelo processo de inserção no mercado internacional. No interior da teorização cepalina-furtadiana, a solução para a superação do "atraso" fazia-se em função da proposição de políticas para a industrialização.

$\mathrm{O}$ traço mais significativo do debate entre as inúmeras correntes desenvolvimentistas dos anos 1950, diz respeito a eficácia da intervenção estatal para a aceleração do crescimento econômico. O centro de toda a discussão sempre foi o 
Estado e a definição do seu papel no desenvolvimento econômico. A não propensão das relações de classe no mundo capitalista à aceitação das suas longas jornadas de trabalho rotinizado correspondentes ao padrão de acumulação taylorista-fordista, em um primeiro momento, levaram ao quase colapso do capitalismo na década de 1930, o que fez com que as sociedades capitalistas se vissem obrigadas a conceber um novo modo de regulação capaz de acomodar a disseminação da produção de massa nos países industrializados. A mão invisível do mercado não foi suficiente para garantir a estabilidade das relações sociais capitalistas, gerando a discussão entre os economistas ortodoxos, liberais ou neoclássicos - adeptos do laissez-faire - e os economistas heterodoxos, keynesianos e estruturalistas, que afirmavam a função do Estado como estabilizador das economias nacionais.

Tendo em conta sua raiz keynesiana, a ação estatal no processo de desenvolvimento aparece no pensamento cepalino como uma consequência natural do diagnóstico dos problemas estruturais de produção, emprego e distribuição de renda nas condições específicas da periferia subdesenvolvida. Diante da insuficiência do desenvolvimento dos mecanismos de mercado na periferia, os conceitos de planejamento e programação surgem como chave para conferir racionalidade e sistematicidade à política econômica latino-americana da industrialização, sendo elaborados principalmente nos documentos da CEPAL dos anos 1950 e tendo Celso Furtado como um dos principais autores de sua parte conceitual.

O planejamento nas economias subdesenvolvidas, na ausência de mecanismos de mercado que funcionem como nas economias centrais capitalistas, tem a função de técnica de alocação de recursos. O planejamento é uma técnica neutra: essa é uma das teorizações mais ideológicas do esquema cepalino-furtadiano, a qual projetou negativa influência sobre as gerações de cientistas sociais (OLIVEIRA, 2003: 29).

A intervenção do Estado em moldes keynesianos tornou-se paradigmática após 1945 e sua interpretação tornou-se hegemônica nos países centrais e na periferia mesmo que nessa última os governos na maior parte das circunstâncias tenham optado pela utilização de políticas macroeconômicas ortodoxas, de corte conservador moldando a ideologia do desenvolvimento que se consolidou na América Latina, principalmente no período do populismo. A reflexão sobre o papel e sobre a natureza do Estado voltou-se essencialmente para orientar a discussão, a pesquisa e as políticas 
concretas de caráter alfandegário, tributário, cambial, fiscal e social voltadas para a industrialização da região nas décadas subsequentes.

\section{Considerações finais}

Na América Latina, a ideologia do desenvolvimento adquiriu especificidades e foi marcada pela influência do pensamento da CEPAL, que produziu um corpo teórico próprio e original, tendo como objeto de estudo a realidade econômica e social latinoamericana. Entre os precursores das teorizações cepalinas, Celso Furtado foi que mais se destacou, foi o intelectual que mais publicou sobre a formação econômica e social brasileira e sobre a especificidade do nosso desenvolvimento. Aqui, buscou-se apresentar as linhas gerais das análises cepalino-furtadianas, que representaram uma contribuição mundial para o pensamento econômico na discussão do problema do subdesenvolvimento.

O resgaste da obra de Furtado mostra-se fecundo na direção da reconstrução histórica da ideologia do desenvolvimento como chave de leitura da política educacional brasileira. A ideologia do desenvolvimento e o enfoque metodológico neoclássico materializam-se, no campo educacional, em concepções como capital humano (FRIGOTTO, 2006), que se redefine a partir da ideologia das competências e da ideologia do capital social, no final do século XX, concepções gestadas nos centros hegemônicos do capitalismo que reordenam as relações de trabalho e educação e fundamentam as políticas de educação e de formação de trabalhadoras e trabalhadores, e adquirem especificidades sob a lógica do capitalismo dependente brasileiro (PARANHOS, 2010).

O aprofundamento teórico em relação aos processos históricos a partir dos quais se originam e são difundidas as chamadas teorias do desenvolvimento, permite desvelar o caráter ideológico do desenvolvimento e a sua relação com o ideário educacional. O combate de qualquer discurso ideológico requer o estudo de seus conteúdos particulares e históricos, no intuito de desnaturalizá-lo, proporcionando para uma análise dos processos sociais mais complexos, através dos quais ele foi se constituindo como discurso hegemônico no campo político-intelectual ao longo dos últimos 70 anos. 


\section{Referências bibliográficas}

BAER, Mônica et al (1995). Os desafios à reorganização de um padrão monetário internacional. Economia e Sociedade, Campinas, n.4, pp. 79-126, jun.

BIELSCHOWSKY, Ricardo (2000). Cinquenta anos de pensamento na CEPAL, uma resenha. In: BIELSCHOWSKY, Ricardo (org). Cinquenta anos de pensamento na CEPAL. Rio de Janeiro: Record.

FRIGOTTO, Gaudêncio (2006). A produtividade da escola improdutiva: um (re)exame das relações entre educação e estrutura econômico-social capitalista. São Paulo: Cortez.

FURTADO, Celso (1974). O mito do desenvolvimento econômico. Rio de Janeiro: Paz e Terra. . (2009). Desenvolvimento e subdesenvolvimento. Rio de Janeiro: Contraponto; Centro Internacional Celso Furtado.

. (2011). Raízes do subdesenvolvimento. Rio de Janeiro: Civilização Brasileira.

MORAES, Reginaldo Carmello de (2006). Estado, desenvolvimento e globalização. São Paulo: Editora da UNESP.

- (2005). Nota sobre a economia do desenvolvimento nos "vinte e cinco gloriosos" do pós-guerra. Cadernos CEDEC, São Paulo, ago.

OLIVEIRA, Francisco (2003). A navegação venturosa: ensaios sobre Celso Furtado. São Paulo: Boitempo.

PARANHOS, Michelle Pinto (2010). Teoria e ideologia do desenvolvimento capitalista: na abordagem das concepções educacionais e das políticas públicas de formação dos trabalhadores no Brasil. Dissertação (Mestrado em Políticas Públicas e Formação Humana) Universidade do Estado do Rio de Janeiro, Rio de Janeiro.

PRADO, Fernando Correa (2015). Ideologia do desenvolvimento e a controvérsia da dependência no Brasil contemporâneo. Tese (Doutorado em Economia) Universidade do Federal do Rio de Janeiro, Rio de Janeiro.

Artigo recebido em 15 de julho de 2020.

Aprovado em 18 de novembro de 2020.

DOI: $10.12957 /$ intellectus.2020.54308 